\title{
Governança para a Territorialidade e Sustentabilidade: a construção do senso de regionalidade
}

\section{Governance Towards Territorial Sustainable Development: building a sense of regionality}

\author{
Luciano Marcelo França \\ Mestre em Desenvolvimento Regional. Pesquisador do Núcleo \\ de Políticas Públicas do Programa de Pós-Graduação em De- \\ senvolvimento Regional (PPCDR) da Universidade Regional de \\ Blumenau (FURB). \\ Endereço: Rua Antônio da Veiga, 140, CEP 89010-971, Blumenau \\ SC, Brasil. \\ Email: Imf.univœgmail.com

\section{Oklinger Mantovaneli Júnior} \\ Doutor em Ciências Sociais. Professor do Programa de Pós-Graduação \\ em Desenvolvimento Regional (PPGDR) da FURB. \\ Endereço: Rua Antônio da Veiga, 140, CEP 89010-971, Blumenau \\ SC, Brasil. \\ Email: oklingerळfurb.br

\section{Carlos Alberto C. Sampaio} \\ Pós-Doutor em Ecossocioeconomia e Cooperativismo Corporativo. \\ Professor do Programa de Pós-Graduação em Desenvolvimento \\ Regional (PPGDR) da FURB e Colaborador do Programa de Pós- \\ Graduação em Meio Ambiente e Desenvolvimento (MADE) da \\ Universidade Federal do Paraná (UFPR). Pesquisador do CNPq. \\ Endereço: Rua Antônio da Veiga, 140, CEP 89010-971, Blumenau \\ SC, Brasil. \\ Email: carlos.cioceœgmail.com
}

\section{Resumo}

No atual contexto das abordagens multiescalares, espacial e setorial das propostas de gestão pública, a regionalidade vêm ganhando destaque na medida em que a complexidade administrativa aumenta por conta da modificação das demandas sociais. Neste contexto, torna-se desafiadora a correlação entre governança, territorialidade e sustentabilidade. Inspirados neste contexto e a partir de uma pesquisa bibliográfica sobre os temas, realizou-se uma análise das relações políticas entre os integrantes do Conselho de Desenvolvimento da Secretaria de Desenvolvimento Regional (SDR) de Blumenau. A pesquisa é descritiva, baseada em entrevistas semiestruturadas realizadas com membros do conselho da SDR no período de sua criação, 2003, até 2008. O modo como a SDR está estruturada, bem como a forma que seus municípios enxergam a si mesmos e aos outros neste contexto, produzem propostas de intervenção e prática institucional que assimilam demandas individuais e coletivas, mas também transformam em certo grau a organização política e econômica da região de sua abrangência. Como uma política que se declara em busca da descentralização, inicia-se em Santa Catarina a experimentação de uma dinâmica desenvolvimentista que busca a homogeneidade e o nivelamento da região em questão esta lógica é perceptível na medida em que os municípios pertencentes a uma regional assumem seus problemas, sobretudo de educação e saúde, por tratarem de atividades de natureza pública, e aqueles dos municípios vizinhos com potencialidades e representatividades políticas diversas. Isto foi explorado a partir das ideias de sustentabilidade política e administrativa que conduza a um desen- 
volvimento inclusivo e harmonizador propiciado pelas instâncias formalizadas e legitimadas pela institucionalidade que os suporta.

Palavras-chave: Governança; Território; Descentralização; Sustentabilidade Política e Administrativa.

\section{Abstract}

The goal of this article is to present an analysis of the politic relations between the participants of the Secretary of Regional Development (SRD) in Blumenau. It is an interdisciplinary research and that can be understood from the so-called environment sciences. The studied aspects to supply crucial data for this research are the political relationship between the cities and with the state government. The structure of the SRD, as well the way cities evaluate themselves, resulted in proposals of intervention and institutional practices that assimilates individual and collective demands, and also shapes somehow the economic and politic organizations in its scope. Previously, the process of development was local and focused on an individual region that was defined by the irregular creation of new cities within the same region. The implementation of this decentralization model promotes the experimentation of a developmental dynamic, that intents to create homogeneity and the flatness of a region. This logic is perceptible as the cities belonging to a same regional assume their problems, overall the education and health, because they can be understood like public activities, and their neighbor's cities problems with several potential and politic representatives. This occurs by sustainable political and administrative procedural that promote an inclusive development and harmonized, propitiated by the formal instances and legitimized by the institutionalism which supports them.

Keywords: Governance; Territory; Decentralization; Political and Administrative Sustainability. 


\section{Introdução}

Atualmente as questões regionais - e com elas a regionalidade - vêm ganhando destaque, na medida em que a complexidade administrativa e política aumenta por conta da modificação das demandas sociais, tais como educação e saúde.

Durante algum tempo, o fenômeno da globalização figurou como argumento principal passando a ser praticamente um consenso quando se falava em uma modalidade consistente de desenvolvimento, daí tudo se conformava para facilitar este fato social.

Os qualificadores deste discurso voltavam-se ao argumento de que o mundo passou a ser uma aldeia global; as fronteiras já não têm mais o mesmo significado e desenho que tinham anteriormente, sendo que disso derivaria a necessidade de um reexame das estruturas e práticas sociais estabelecidas.

Não que se perceba, e não é essa a intenção, que este argumento foi em sua totalidade esvaziado, pois para sua refutação seria necessária uma pesquisa à parte e qualquer tentativa superficial seria de um proceder irrefletido. Entretanto, o que definitivamente a globalização não significa é uma resposta para se alcançar o desenvolvimento humano num sentido mais amplo do termo - saúde, educação, habitação e renda - pois as condicionantes do desenvolvimento residem mais nas políticas (em termos de conteúdos) de organização interna, modelos relacionais, aspectos políticos e administrativos, capacidade endógena, do que nas modalidades comerciais. De outra parte, as dinâmicas (em termos de processos) que o determinam apresentam tantas heteronomias que o próprio protagonismo se dilui sistemicamente, passando a ser determinado por um status quo inadvertidamente perpetuador das desigualdades, da fluidez inconsistente das agendas, da capacidade de financiar prioridades. Portanto, falar em um padrão de sociabilidade saudável é dizer dos aspectos idealmente representativos de uma sociedade plural e democrática. Toma-se aqui a noção de saúde em seu sentido lato, amplo, compreendendo-a também como expressão de relações sociais reciprocamente determinadas entre um ambiente saudável e suas interfaces políticas (Sampaio, 2001; Philippi Jr, 2009).
Assim, desta leitura de mundo surge um ponto de inflexão que indica a vertente de pensamento que concebe o desenvolvimento calcado na regionalidade. Desta forma começa a surgir uma maneira de entender o espaço habitado, reconhecendo que é possível alcançar o desenvolvimento baseando suas ações em modelos regionais que dão identidade a esse processo.

Por esta perspectiva, o desenvolvimento expresso a partir do senso de regionalidade, por meio de determinações político-processuais, passa a ser observado com muita constância, uma vez que os atores governamentais parecem crescentemente tomar a regionalidade como espinha dorsal de um desenvolvimento mais equitativo. Isto é o que o discurso do estado catarinense sugere, a incorporação de tais elementos. Entende-se que, em nível normativo de análise, o senso de regionalidade na Secretaria de Desenvolvimento Regional (SDR) de Blumenau, deveria resultar uma institucionalidade que movimentasse as políticas públicas de forma coordenada, equilibrada e sustentável. A prática institucional, as propostas de intervenção e os acordos políticos a elas subjacentes contribuem para que em uma perspectiva multissetorial espacializada, um senso de regionalidade se edifique. Na gestão pública das dinâmicas voltadas ao Desenvolvimento Territorial Sustentável nem sempre os interesses serão comuns e compartilhados pelos membros envolvidos: pactos se estabelecem pela gestão do empilhamento e escalonamento dos interesses.

A proposta de descentralização oferece uma estrutura e um modelo de gestão calcado num certo grau de participação de vários segmentos da sociedade. Este processo é eminentemente político, na medida em que se ocupa de negócios públicos e conta com a participação de vários atores sociais. O fenômeno relacional propiciado pela governança como instância de pactuação produz contornos que formatam uma territorialidade e esta , como produto, é tratada como objeto de estudo, pois oferece entendimento de como ocorre o processo com sustentabilidade política e administrativa.

O problema aqui postulado concentra-se precisamente nisto, a pactuação como produtora de um processo político/administrativo que será percebido como sustentável ou não, na medida em que propicie 
determinado senso de regionalidade como premissa de uma política virtuosa, por conseguinte, de uma sociedade saudável. A partir deste, surge o objetivo de avaliar o processo de governança no Conselho de Desenvolvimento da Secretaria de Desenvolvimento Regional de Blumenau para perceber qual territorialidade resulta deste processo.

\section{Metodologia}

Este tema perpassa pela pesquisa interdisciplinar e que pode ser compreendida nas chamadas ciências ambientais. A pesquisa desenvolvida é de natureza qualitativa do tipo descritiva. Tratam-se de dados e informações colhidas no conselho da SDR de Blumenau, composta pelos municípios de Blumenau, Gaspar, Ilhota, Luiz Alves e Pomerode, a partir de entrevistas semi-estruturadas. A intencionalidade da amostra se caracterizou pela escolha dos conselheiros que integram a SDR de Blumenau no período de sua criação (do conselho), em 2003, até 2008. Foram entrevistados 10 (dez) membros, 02 (dois) integrantes de cada um dos 05 cinco municípios participantes ou membros da secretaria. Existe consistência nesta amostra, na medida em que, desde sua criação até agora, pouco se alterou em sua estrutura em termos de conselheiros.

\section{Governança}

Quanto mais se apuram as técnicas e ferramentas de comunicação (e isto ocorre num ciclo cada vez mais rápido, transformando o contexto) e mais atores sociais passam a participar dessa complexidade relacional. $\mathrm{O}$ viver em sociedade denota em algum momento uma disposição articulada de pessoas, recursos e espaços com interesses particulares ou coletivos. Essa articulação entre pessoas, bens, recursos, interesses, habilidades e conhecimentos nos conduz a pensar o homem como ser organizacional; naturalmente, este conceito transcende a mera percepção de organização como espaço de produção e comércio, e implica em uma organização do ponto de vista social ampliado como expressa Etzioni (1980). Este autor reconhece a vida em sociedade como uma vida organizacional com caráter objetivo/instrumental num dado momento e substantivo em outro:

A nossa sociedade é uma sociedade de organizações. Nascemos em organizações, somos educados por organizações, e quase todos nós passamos a vida a trabalhar para organizações. Passamos muitas de nossas horas de lazer a pagar, a jogar e a rezar em organizações. Quase todos nós morremos numa organização, e quando chega o momento do funeral, a maior de todas as organizações, o Estado - precisa dar uma licença especial (Etzioni,1980).

Este ir e vir, transitando o homem por vários ambientes como agente e transformador (nem sempre harmonizador), como delimitador de espaços e territórios (tangíveis e intangíveis), formando alianças e parcerias, sejam elas de curto ou de longo prazo, acomodando interesses e desenvolvendo estratégias para superar fragilidades do processo, mas, sobretudo caracterizando este movimento como fenômeno relacional e sem dúvida político. Destas relações e negociações emergem pactos, sendo que este conceito estruturante ${ }^{1}$ incorpora e é incorporado pelas características sociais vigentes. Isto fica caracterizado na visão de Mário Procopiuck e Klaus Frey, quando assinalam que:

Nessas estruturas de organização para articulação sociopolítica, consequentemente, os atores deixam de ser representados como simples conjuntos amorfos de participantes em eventos isolados. Em termos analíticos, passam a ser considerados ativamente a partir da gênese de sistemas relacionais que ganham forma e consistência no decorrer do tempo, originando complexas estruturas de governança com identidade própria em torno de conteúdos específicos de políticas que lhes interessam. Nessas estruturas, com diferentes níveis de coesão relacional, o posicionamento e as capa-

\footnotetext{
1 O subsistema estruturante descrito por Alberto Guerreiro Ramos (1983) é composto pelas decisões de natureza política, estratégica, tática ou operacional. As decisões estruturam a empresa (com equipamentos, recursos financeiros, material de consumo etc.), mobilizam a energia subjetiva do fator humano (a motivação, os valores e as emoções positivas) e, além disso, estabelecem parâmetros legais (estatutos, manuais etc.), orientadores de desempenho com vistas aos objetivos empresariais. RAMOS, A. G. Administração e contexto brasileiro. Rio de Janeiro: FGV, 1983.
} 
cidades de articulação de cada agente individual para afetar os resultados coletivos nas decisões políticas são os meios disponíveis para interferir no curso de suas próprias ações e das dos demais atores (2009, p. 66).

O conjunto social moderno é formado por elementos característicos, que o faz assumir um formato multidimensional, tornando-se cada vez mais complexa sua compreensão e administração. Ao longo da história recente assistimos a uma democratização do processo informacional em nível mundial e isto fez florescer uma nova sociedade, caracterizada por uma nova lógica que repercute numa mecânica (reterritorialização) alimentada por outros insumos. O conceito de governança volta-se a fenômenos da política, expressivos na era moderna e contemporaneamente de algumas particularidades. Quando se fala em governança, o senso de reciprocidade entre atores, estruturas e institucionalidades, torna-se presente no campo da análise e no universo propositivo das políticas públicas. Para Álvares e colegas (2008), são atendidos a certos pré-requisitos sistematizados que dão forma e significado ao conceito e isto se caracteriza quando:

A abordagem integrada está presente nos elementos de análise do modelo. Deles fazem parte os conceitos da escola formalista baseada no atendimento dos dispositivos legais dos órgãos reguladores e na aderência à prática dos princípios de fairness (lealdade), compliance (conformidade), acountabilities (prestação de contas) e disclosure (transparência). Esses elementos de análise incluem e privilegiam, os conceitos construtivistas do processo de governança (p. 17).

Os objetos ${ }^{2}$ em si continuam sendo os mesmos, como caracteriza o autor. Entretanto, do ponto de vista conceitual, metodológico e da própria estrutura, houve um processo de sutilização que é resultante de radicais transformações das demandas sociais. Este é um sinal da transição de um modelo ${ }^{3}$ para outro, como explica Jorge Werthein, no trecho a seguir:
A realidade que os conceitos das ciências sociais procuram expressar refere-se às transformações técnicas, organizacionais e administrativas que têm como "fator-chave" não mais os insumos baratos de energia - como na sociedade industrial - mas os insumos baratos de informação propiciados pelos avanços tecnológicos na microeletrônica e telecomunicações. Esta sociedade pós-industrial ou “informacional”, como prefere Castells, está ligada à expansão e reestruturação do capitalismo desde a década de 8 o do século que termina. As novas tecnologias e a ênfase na flexibilidade - idéia central das transformações organizacionais - têm permitido realizar com rapidez e eficiência os processos de desregulamentação, privatização e ruptura do modelo de contrato social entre capital e trabalho característicos do capitalismo industrial (2000, p. 71).

Baseado num princípio claro de institucionalidade, este, como todo fenômeno político administrativo, reflete a necessidade de buscar uma equação que promova a contemplação das diversas perspectivas, dos diversos olhares sobre o mesmo objeto. Nessa direção, a Comissão sobre Governança Global, da Organização das Nações Unidas, reconhece-a como instância mediadora dessa pactuação com perceptível intencionalidade do seu propósito, e resulta no entendimento de que:

Governança é a totalidade das diversas maneiras pelas quais os indivíduos e as instituições, públicas e privadas administram seus problemas comuns. É um processo contínuo pelo qual é possível acomodar interesses conflitantes ou diferentes e realizar ações cooperativas. Governança diz respeito não só a instituições e regimes formais autorizados a impor obediência, mas também a acordos informais que atendam aos interesses das pessoas e instituições (Comissão sobre Governança Global, 1996).

Este conceito revela em primeiro plano a participação de vários atores sociais, cada qual com suas demandas e seus entendimentos que podem ou não estar de acordo, que podem ou não coexistir ${ }^{4}$. Num

\footnotetext{
2. Capital e sociedade

3 Modelo que privilegiava a produção industrial para um modelo que privilegia a informação

4 Cabe ressaltar que a pactuação, essência da governança não deseja por si ser uma mera produtora de acordos, antes disso, a preocupação com o fundamento, a constatação de atores, interesses e posições.
} 
outro plano de análise, ainda é possível reconhecer que a sobreposição de interesses ou necessidades, tratado de alguma forma pela institucionalidade que produz uma pactuação (territorialização), por sua vez transforma em algo inteligível e concede um caráter fluido à administração como process , na medida em que se busca o entendimento, a facilitação de negociações e o atendimento total ou parcial de interesses.Isto pode ser reconhecido como consenso estratégico, estando este pensamento contido nas palavras de Ariel Raidan:

El Estado como bien es protagónico para direccionalizar un modelo de desarrollo. Contribuye en esta dirección la importancia de la planificación y de una visión estratégica que impulse un proyecto. Es clave para salir del coyunturalismo, tener una hoja de ruta y un consenso estratégico. Porque el Estado no es sólo una dimensión jurídica, normativa o de articulación de relaciones sociales y de gestión, sino también es un proyecto colectivo. Porque planificar un rumbo no es sólo un problema económico sino integral, que requiere una construcción plural con diversos actores e instituciones. En todo caso, así como ya se demostrara la inviabilidad de dejar todo en manos del mercado, tampoco puede ser un plan sin amplios consensos sociales, sino un plan elaborado en un proceso consensuado entre diversos actores que comparten un mismo horizonte sobre le desarrollo y el papel del estado. (2009, p.13)

Sob o olhar de Leonardo Valles Bento, a governança é um fenômeno muito mais instrumental, com características burocráticas, e este por sua vez como agente formalizador da institucionalidade na qual se contextualiza, por fornecer ferramentas administrativas objetivas eficientes. Este pensamento fica claro quando define que: "Governança diz respeito aos pré-requisitos institucionais para a otimização do desempenho administrativo, isto é, o conjunto de instrumentos técnicos de gestão que assegure a eficiência e a democratização das políticas públicas" (2003, p. 85). Entretanto, é importante ressaltar que esta definição bem como sua compreensão, não deverão evocar a hipótese de um mero engendramento estrutural estático e estanque em si mesmo: trata-se de uma representação que deve em algum grau se automodelar e se autotransformar, acompanhando a dinamicidade e mutabilidade do ambiente, suas características, os atores que a compõem gerando uma nova territorialidade a cada momento em que se institui, produzindo em cada fase uma nova pactuação, com nova forma e conteúdo. Isso não quer expressar a incorporação da administração pela governança, mas da sua utilização, propiciando resultados palpáveis num processo rastreável e que expresse o interesse da coletividade.

O que fica claro no transitar pelos conceitos e percepções sobre a governança como categoria conceitual pura, é que lhe falta subsídio teórico, se for analisada isoladamente; entretanto, quando esta vem acompanhada de outras categorias conceituais, o esforço de entendimento e compreensão são facilitados pela utilização do tema em contraposição a outro, que gera um contraste revelador. Para tanto, se elegem algumas categorias que se consideram relevantes para explicar o objeto, contemplando as dimensões que respondem ao recorte feito.

A governança na esfera pública confere aos governos eficácia como prestador de serviços à sociedade, dando maior lisura ao processo administrativo público, trazendo à tona preocupações de bastidores, de como as coisas são definidas, da sua relevância e dos resultados para a coletividade.

Para este fim, acaba-se criando uma forma de estrutura conceitual e de princípios baseados nos grupos formais e informais, com alguma influencia política ou administrativa, em que se privilegia o acesso e a visibilidade processual de organizações num sentido mais amplo. A soma destas partes consolidadas pela governança em suas várias aplicações, interpretando e condicionando os pactos nos mais diversos arranjos sociais, permite às ações de governo se fazer presentes em esferas onde seu alcance seria limitado por outros meios administrativos, permitindo então pelo pressuposto da governança o alcance da governabilidade que em seu momento será abordada e caracterizada.

Também resulta como dimensão importante para nosso estudo a distinção entre governança e governabilidade. 0 emprego do conceito de governança como instância facilitadora do processo político faz emergir ferramentas e práticas objetivas que permitem o exercício do governo. Assim, fica nítida a importância da governança para a governabilidade 
como sustentadora do processo político, uma vez que se ocupa de reconhecer e estudar os pactos e seu resultado. A política como fenômeno social permeando as instâncias de governo nos parece indissociável do conceito de governança, e esta por sua vez, carregada desse conceito propicia a governabilidade.

\section{Sustentabilidade e Sustentação Política e Admi- nistrativa}

Nas argumentações que dão sentido à sustentabilidade política e administrativa, percebemos de forma clara a inserção da variável governança, pois abandona a hipótese da análise apenas dos resultados, preocupando-se com o modo pelo qual estas foram engendradas. Não estamos afirmando aqui que, pelo fato de haver uma preocupação fundamental com os resultados, não exista ali um traço claro também de governança/pactuação no produzir destes resultados. 0 que passa agora a figurar como categoria principal, na perspectiva da sustentabilidade/ sustentação política e administrativa, é o fato de haver um acompanhamento estrito sobre o processo decisório e, sem dúvida, da administração do ponto de vista processual. Agora a avaliação deste processo ganha caráter qualitativo das ações administrativas e políticas, que por si, passa a resguardar não mais só critérios de "eficiência e eficácia", como descrito pelos autores; ela compreende e transfere o processo avaliativo para o "como":

Na medida em que os processos são vistos como determinantes fundamentais da política e seus resultados, estes se tornam, também alvo privilegiado dos processos decisórios. Ou seja, os atores começam a se preocupar com a abordagem aplicada ao processo decisório, suas pedagogias, sua normatividade, suas prerrogativas, sua dinâmica, e passam também a deter este conhecimento e com ele lidar (Mantovaneli Jr e Sampaio, 2007, p. 13).

Este entendimento dos processos políticos e administrativos vai com o tempo refinando e fortalecendo os laços entre sociedade civil organizada e instâncias de governo ou de onde a perspectiva política parte. Dessa forma, existe grande tendência de ocorrer uma significativa melhora do(s) resultado(s), pois a qualificação e visibilidade do processo assinalam para um resultado mais assertivo. Toma-se aqui, portanto, a idéia de sustentabilidade ou sustentação, relativizada no sentido de identificar, nos objetivos formais da política em análise, o desejo de promover o desenvolvimento territorial com democracia e sustentabilidade (Sachs, 2007; Vieira, 2009). Na medida em que este componente não seja observável em nível formal e/ ou declarado, o que passa a ganhar destaque é o componente da sustentação. Sustentação política estaria relacionada ao fenômeno da Politic, ou seja, a dinâmica de poder e interesses subjacentes ao fenômeno social, e a gestão do interesse público, objetivando reordenar a arquitetura institucional e processual organizativa no sentido de ajustar os determinantes técnicos aos objetivos propostos, na proporção em que as diretrizes políticas assumidas e pactuadas assim o determinem. Na medida em que essas diretrizes assumem a correlação entre sustentabilidade e democracia, o fenômeno passa a ser nominado não mais como sustentação política e administrativa, mas sustentabilidade política e administrativa.

\section{Espaço, Regionalidadade e Territorialidades}

O estudo da territorialidade é necessário, na medida em que se pretende compreender de que forma são construídos ambientes intangíveis que fazem materializar e consolidam (ou não) as políticas, comportamentos e relacionamentos, sejam eles quais forem, conferindo-lhes características próprias e indissociáveis.

Não há como não relacionar a temática da territorialidade com a do espaço, afinal sobre o espaço e suas diversas dimensões se dão todos os outros fenômenos físicos ou eminentemente intangíveis. Para tanto, se traz à tona elementos fundamentais que compõem a totalidade percebida como:

[...] as categorias fundamentais do conhecimento geográfico são, entre outras, espaço, lugar, área, região, território, habitat, paisagem e população, que definem o objeto da geografia em seu relacionamento. [...] De todas, a mais geral - e que inclui as outras - é o espaço (A.C. da Silva, 1986, citado por Santos, 1994, p. 70-71). 
O espaço, categoria apropriada pela geografia, que reconhece várias nomenclaturas que na visão do autor parecem insuficientes para explicar de modo amplo a complexidade e a dinâmica dos eventos. Por isso, percebe que a mais abrangente e que acaba suportando todas as outras (citadas anteriormente por Milton Santos) neste raciocínio é o espaço. Para Milton Santos, numa definição mais aprimorada temos que:

O espaço seria um conjunto de objetos e de relações que se realizam sobre estes objetos; não entre estes especificamente, mas para os quais eles servem de intermediários. Os objetos ajudam a concretizar uma série de relações. 0 espaço é resultado da ação dos homens sobre o próprio espaço, intermediados pelos objetos, naturais e artificiais (Santos, p. 71, 1994).

Esta definição de espaço mergulha na interpretação caótica de vários elementos, relacionados entre si ou não, mas que sobretudo pela intervenção humana resultam num espaço que se modifica constantemente segundos as relações que se estabelecem sobre ele. Diz ainda em seu conceito que "os objetos ajudam a concretizar as relações". Estes objetos podem ser entendidos como os recursos à disposição que, segundo a facilidade de acesso a eles, interferem com as relações de formas diversas; por conseqüência, o resultado que produzem também é variável e condicionado, sendo que estes recursos ou variáveis mudam uns aos outros, influenciando o resultado do outro. Esta reconstrução continuada se dá em função da dinamicidade das relações entre as pessoas e destas com as coisas, na proporção em que reinventam métodos e práticas inserindo novas tecnologias, na acepção mais ampla do termo. 0 autor continua: "A espacialização é um momento da inserção territorial dos processos sociais. 0 espaço é mais do que isso, pois funciona como um dado do próprio processo social” (Santos, 1994, p. 73). Assim, definitivamente o espaço é algo que existia antes de nós, já produzia a si mesmo de forma natural e cíclica, continua produzindo a si mesmo dessa mesma forma, mas a partir do homem ou do processo evolutivo tecnológico menos integrativo e harmonioso, resulta numa mistura da intervenção humana (processos sociais) e do seu prosseguir natural. São duas forças que agem de forma desequilibrada: em alguns momentos a atividade humana (mais predominante) mais intensa, acelerando processos naturais, em outros momentos os processos naturais agravando e complexificando as relações; estas duas se entrelaçam e produzem uma nova forma continuamente. "Espaço refere-se à totalidade dos lugares, entendendo lugar como a expressão da dimensão global, produzido na articulação contraditória entre a mundialidade e a especificidade" (Dallabrida apud Siedenberg e col., 2006, p. 84). 0 autor entende o espaço de forma generalista (ou como totalidade) neste momento, assim caracterizado na soma dos lugares, enxergando a regionalidade como produto do todo ou influenciado por ele. E o autor evolui em sua caracterização, indicando que "[...] o espaço é formado por um conjunto indissociável, solidário e também contraditório, de sistemas de objetos e sistemas de ações, não considerados isoladamente, mas como um quadro único no qual a história se dá" (Dallabrida apud Siedenberg e col., 2006, p. 84). 0 autor analisa o espaço como uma produção em conjunto, indicando que se deve reconhecer o espaço no resultado total, mas que é produzido na particularidade e na relação desta com a totalidade. Por este motivo reconhece como sistemas as relações entre as coisas e das coisas com ação das pessoas; nesta ação e relação social reside a pactuação produtora de cenários e formatos (inéditos ou não) que condicionam a disposição espacial e sua organização.

Originariamente o conceito de espaço cunhado pela geografia, pressupõe uma categoria mais tangível, tratando de questões como a morfologia do planeta (em hipótese alguma temos a intenção de afirmar que a geografia se resume a isto). 0 que temos a intenção de destacar é que o espaço como conceito, ou a espacialidade em si, se mostram insuficientes quando tentam refletir maior abrangência. Desta forma o estudo do território e da territorialidade atinge uma categoria conceitual que dá conta não só de questões físicas, mas, sem dúvida e principalmente, de questões abstratas da ação humana. Estas questões abstratas às quais se referem resultam do fenômeno relacional social que produz modificações importantes, de ordem física/ tangível ou abstrata/intangível.

De todo modo, para se iniciar a discussão, reconhece-se nas palavras de Rogério Haesbaert que: "As 
formas mais familiares de territorialidade humana são os territórios juridicamente reconhecidos, a começar pela propriedade privada da terra, mas a territorialidade se manifesta em diversos outros contextos sociais" (2006, p. 84). Naturalmente, é impossível tratar de qualquer dimensão de território e de territorialidade, sem que se passe pela concepção de território físico, do espaço físico onde se produz todos os outros tipos de territorialidades derivadas da concepção humana; assim, o autor condiciona a construção de qualquer tipo de territorialidade à mais fundamental delas, que é a territorialidade física da terra, como espaço natural. Ao analisar o território ou a territorialidade numa dimensão intangível, que por si se traduz em questões eminentemente simbólicas, alcança-se a concepção do entrelaçamento conceitual da perspectiva da pactuação e da territorialidade assim tratadas. As relações sociais produzem territorialidades; estas, como matéria de realimentação, produzem pactos que por sua vez produzem novas relações, num ciclo interminável de modificação de suas praticas em função do surgimento de novas variáveis assimiladas durante o processo. "O poder do laço territorial revela que o espaço está investido de valores não apenas materiais, mas também éticos, espirituais, simbólicos e afetivos. É assim que o território cultural precede o território político e com ainda mais razão precede o espaço econômico" (Bonnemaison e Cambrèzy, citado por Haesbaert, 2006, p.72). No entendimento do território como elemento intangível produto da ação humana, percebe-se na caracterização do autor dois aspectos: além de uma interdependência dos elementos, evidenciada pela demonstração de que um acaba sendo consequência do outro, também fica nítida a imbricação que envolve o conceituar estes elementos.

\section{A Experiência da Secretaria de Desenvolvimento Regional (SDR) de Blumenau}

O conselho da SDR de Blumenau segundo o que descreve a legislação e a formatação desta política administrativa tem de um lado o governo central (Governo do Estado de Santa Catarina) e do outro lado, representantes da sociedade civil organi- zada, como também os representantes políticos municipais. É constituído por 13 membros, assim distribuídos: são 7 membros natos, o secretário de desenvolvimento regional, prefeitos dos municípios membros e os presidentes das câmaras de vereadores; os 6 restantes são 2 representantes da sociedade civil organizada (setores cultural, educacional, político, ambiental, econômico). Estes têm direito a voto e sua permanência coincide com seus mandatos. Além destes, há representantes da secretaria da fazenda, da secretaria da segurança pública, da polícia militar e do corpo de bombeiros (militar),sendo que estes membros não tem direito à voto: seu papel é oferecer um parecer técnico e dar suporte às ações e decisões dos conselheiros (ainda que estejam vinculados ao poder do governo do estado). Estes membros do conselho permanecem nos cargos por nomeação durante no máximo 4 anos. Assim é formado o corpo de conselheiros e membros, que tem a responsabilidade de servir de porta-voz das demandas dos municípios da região da SDR de Blumenau, sobretudo integrando-os, para que como conjunto possa alcançar um patamar de desenvolvimento coerente com a capacidade física, financeira e política de cada regional aproximando o governo de onde a necessidade ocorre e de onde surgem os problemas. Nessa lógica, não existe uma série de elementos complicadores do ponto de vista de estrutura, ou seja, esta metodologia horizontaliza a estrutura administrativa e a torna muito mais ágil sob certa perspectiva; evidentemente, existem outras implicações que não são visíveis na forma do objeto.

Quando da sua eleição para prefeito de Joinville, Luiz Henrique da Silveira, no mandato de 1997-2000, foi à Alemanha fazer um curso de administração pública; lá conheceu a metodologia da descentralização que já era utilizada naquele país em certas regiões, bem como no norte da Europa em alguns países. O norte da Europa há muito se destaca como referência em termos de desenvolvimento; este modelo funciona e modifica a realidade tanto administrativa quanto no que se refere a resultados. O então prefeito Luiz Henrique trouxe a metodologia para ser empregada na cidade de Joinville, e lá implementou o modelo regional com repercussão positiva na administração da cidade. Eleito depois 
governador e já tendo experiência na estruturação da descentralização no governo municipal, que de certa maneira acabou servindo de laboratório, estava muito mais a vontade e conseguiu articular a mesma metodologia para o estado como um todo.

A política de descentralização instituída pelo governo do Estado de Santa Catarina tem como principal mérito conseguir reunir num mesmo ambiente vários representantes de várias cidades (integrantes da SDR de Blumenau), com interesses e necessidades em comum. As várias orientações dos conselheiros tornam o ambiente mais diverso, e isto se expressa na pluralidade que propicia a discussão, pois pelo contraditório é possível construir posições que depuram o processo em si. O fato de existir o Conselho das SDR como espaço (arena) formalizado para as discussões resulta em ganho para os representantes dos municípios, na medida em que não existe mais a necessidade de se deslocarem à capital para conseguirem contemplar suas demandas. Na dinâmica de funcionamento anterior o que ocorria era a necessidade de peso político, ou seja, era necessário haver um deputado estadual que defendesse os interesses do município e região na esfera decisória do poder executivo estadual. Essa relação na maioria das vezes era recoberta por um forte traço de fisiologismo político, o que certamente dificultava o processo e as negociações. Essa relação entrópica se dissipa na configuração atual, que traz o secretário do governador para a região, e passa a depender menos dos deputados estaduais e suas respectivas redes para colocar na pauta e cronograma de atendimento as necessidades regionais. A partir da SDR, entretanto, o processo se localiza regionalmente e agora depende da figura do secretário de desenvolvimento regional, que assume uma função de articulador das demandas junto ao governo mas que não tem ainda força ou autonomia para definir livremente as prioridades com seus conselheiros, colocando-as autonomamente para o debate ampliado sobre as questões fundamentais para o estado. Isto relativiza o que formalmente seria uma real descentralização não ultrapassando o nível do exercício formal de desconcentração. Ou seja, se o objeto deste estudo fosse a problematização a partir da temática da descentralização, um sem número de aspectos complicadores facilmente seriam evidenciados. Este ponto reflete a fragilidade do processo de descentralização que merece atenção, e isto já foi objeto de discussão em reuniões da própria secretaria. Assim cada vez mais a SDR de Blumenau vai firmando sua posição de agente mediador como espaço formal, onde se manifestam interesses, necessidades e problemas que de alguma forma acabam por alimentar de informações as instâncias decisórias do governo estadual. Isto, sem dúvida, facilita o acesso das comunidades ao governo, bem como do governo à comunidade, abrindo uma via de mão dupla que está longe da efetividade absoluta, mas que começa a surtir efeitos práticos, alterando o dia-a-dia das pessoas.

A SDR de Blumenau, composta pelos municípios de Blumenau, Gaspar, Pomerode, Ilhota e Luiz Alves, representa para os seus membros um espaço formal e democrático de discussões onde se apresentam propostas para a melhoria das condições de desenvolvimento da região de abrangência da SDR com intencionalidade integrativa. Os membros reconhecem a SDR de Blumenau como um instrumento político complementar (arena ${ }^{5}$ ), pois, existem as secretarias de estado e as prefeituras que se ocupam do suporte estrutural dos municípios pelos quais são responsáveis. A SDR, enquanto foro de discussões e avaliação, está sendo cada vez mais reconhecida como espaço político onde são colocadas posições que, submetidas ao conselho da SDR (norteada pelo seu estatuto e princípios), de certa forma passam a influenciar as ações dos governos locais no que diz respeito à formatação da cidade em função da construção e do fortalecimento da região de abrangência.

É possível reconhecer na composição do conselho várias perspectivas sobre o mesmo objeto, entretanto, a forma de agir dos conselheiros, ainda que impregnada de sua percepção particular, se desloca para a percepção e avaliação das matérias, refletindo a opinião e de certa forma, a personalidade do todo. Resulta disso a impressão de que surge um comportamento dos conselheiros condicionado por aquela

5 Assim entendido por se configurar como um espaço delimitado por regras e objetivos, em que se discutem assuntos de interesse público, por sua vez submetidos e legitimados por esta institucionalidade. 
institucionalidade, mas que acima de tudo reforça o grupo e o espírito de corpo, mesmo em condições de conflito de opiniões. Estes conflitos ou diferenças de opinião enriquecem as discussões ocorridas nas reuniões.

Com relação ao processo de governança, não é demais assinalar que seu entendimento deve expressar o sentido de pactos existentes na sociedade em sua totalidade ou em segmentos dela, sejam estes organizados ou não. No caso da SDR esta pactuação está condicionada por uma instância de poder formalizado que é o governo do estado. 0 primeiro traço de governança se percebe no momento em que o governador eleito pela expressão democrática do voto (pactuação), representando a sociedade do estado, implementa as políticas constantes em sua plataforma de governo. Baseado e a partir deste pressuposto de legitimidade, passa-se a reconhecer também a SDR de Blumenau como espaço verdadeiro (arena) das discussões políticas sobre demandas dos municípios alinhadas ao objetivo da tônica regional. O processo de governança na SDR de Blumenau ocorre em duas vias que se completam, que existem uma em função da outra ou por conseqüência uma da outra.

A primeira via se caracteriza pelo fato gerador, instituído por regras e preceitos definidos previamente, ou na gênese do projeto de descentralização. Esta institucionalização é reflexo de uma pactuação política (governança) que formaliza à SDR como espaço legal. A outra via é percebida claramente pela conveniência dos membros da SDR, dos representantes dos municípios de abrangência da secretaria. Estes interesses se expressam sob a forma com que os conselheiros negociam e propõem suas hipóteses de desenvolvimento caracterizadas em suas demandas, também legitimadas pelo regramento da própria formatação da secretaria. A esta altura se percebe que estas duas vias de governança ou de pactuação acabam se fundindo em apenas uma, a partir daí surge um processo de pactuação determinado normativamente, mas que acomoda interesses diversos buscando uma espécie de equilíbrio dinâmico (entre demandas dos territórios, sejam eles mais ou menos representativos). Ou seja, existe uma adaptação do comportamento dos conselheiros ao formato pré-estabelecido da secretaria, que por sua vez foi concebi- da para atender aos conselheiros e seus respectivos municípios, e disso resulta certamente um alto grau de alinhamento entre o formato da secretaria e das propostas e interesses negociados.

A territorialidade estabelecida pela política de descentralização na forma dos conselhos das secretarias de desenvolvimento regional propicia a aproximação dos municípios integrantes do conselho. Este método ou modelo administrativo pressupõe certo nível de integração e estabelece um formato de relacionamento diferente do que se está acostumado, ou de como usualmente ocorre entre o governo local (municipal) e o governo estadual. Os prefeitos, por serem membros natos (conselheiros), acabam adaptando-se a esta lógica e, de certa forma, replicam alguns efeitos dessa relação em sua própria gestão; com efeito, passa a integrar sua pauta administrativa o cronograma e os movimentos da SDR. Outra questão que chama a atenção é que os municípios sentem-se parte de um todo (SDR), o que lhes oferece um entendimento diferente. Quando o prefeito administra sua cidade isoladamente, ou de modo não integrado, conduz sua administração e sua perspectiva política de uma forma; quando passam a integrar o conselho da SDR, os prefeitos percebem que a lógica e a dinâmica político/administrativa também se transforma. Agora a administração passa a ter uma implicação diferente e mais complexa, pois o prefeito pensa suas ações de governo sabendo que faz parte de um conjunto. Isto ocorre não pelo fato do prefeito assimilar a hipótese desse modelo imediatamente, mas pelo simples motivo de que, se ele não pensar as prioridades de seu município de forma integrada, seus projetos e suas demandas correrão o sério risco de não conseguirem amparo e respaldo da SDR na pessoa de seus conselheiros. Isto faz com que a natureza das relações se modifique substancialmente; as relações às quais se refere são as relações do prefeito (município) com o governo estadual, reduzindo a necessidade da figura do deputado estadual como interlocutor de suas políticas e ações. Por outro lado, reflete também significativa mudança no entendimento de seu próprio município participando de um grupo com interesses similares e necessidades também parecidas. Os prefeitos precisam, a partir da nova metodologia, reconhecer como seus problemas que atingem a região como 
um todo. Este sentimento corporativo propiciado pela participação do município no conselho da SDR proporciona a integração entre eles.

O padrão de governança estabelecido no conselho da SDR de Blumenau tem produzido resultados satisfatórios dentro das possibilidades impostas pelo formato, ou limites impostos pela própria natureza do modelo. Significa dizer que a limitação e o grau de autonomia do conselho são em primeiro plano definidos pelo governo do estado, que determina as regras de funcionamento e é condicionante fundamental das pactuações que dele derivam. Apesar disso, surgem características não previstas na definição inicial da proposta, ou seja, o conselho da SDR de Blumenau desenvolve sua própria "personalidade" com singularidades e especificidades definidas pelo comportamento dos próprios atores sociais. Dentro da perspectiva da limitação de autonomia, surgem territorialidades adaptadas (resultado do padrão de pactuação) às condições possíveis que já foram evidenciadas. O importante, entretanto, neste momento, é reconhecer de que forma ocorre o processo de territorialização e seus resultados. Ainda que hajam de fato perspectivas diversas sobre o mesmo objeto, e interesses também diversos, ocorre a construção de um tipo de relacionamento (pactuação) que pode, num primeiro momento, gerar algum tipo de desconforto, visto que exige a participação de vários atores num mesmo lugar, atores que inicialmente estavam lá para defender apenas seus próprios interesses. No caso em questão, existia também a desconfiança da manutenção de certo caráter hegemônico da maior cidade, que é Blumenau; apesar de inicialmente haverem algumas diferenças, hoje já se percebe significativa diminuição no estado de alerta das outras cidades quando o assunto é o favorecimento da cidade sede da secretaria. Isto se deu pela iniciativa de alguns conselheiros ao longo do relacionamento que se estabeleceu. Podemos usar como exemplo o próprio reitor da universidade que abriu temporariamente projetos como o hospital universitário, que tem muito significado não só para Blumenau e a universidade, mas para toda a região, em função da limitação orçamentária.

A partir do momento que existe o relacionamento entre os conselheiros (atores) sendo este produtivo ou não (sob a perspectiva regional), se estabelece a pactuação (princípio da governança). O grau de pactuação produz a territorialidade, não é o caso de se analisar se esta territorialidade é plena e menos ainda sob a ótica de quem. O que vale reconhecer é que, de fato, o estabelecido como regramento da institucionalidade do conselho se reflete na conduta de seus conselheiros e, por reflexo, no fluxo e funcionamento da secretaria em sua totalidade. Existem convenções estabelecidas objetiva e subjetivamente: a primeira diz respeitoàs que estão descritas e assinaladas no estatuto, ou seja, baseadas em leis amparadas pelo ordenamento jurídico brasileiro que prevê e descreve sua aplicação. A segunda diz respeito a uma série de regras estabelecidas intrinsecamente, que é como uma "regra de civilidade". Pode-se fazer essa leitura pelo comportamento dos conselheiros, que tomam alguns cuidados quando estão atuando. Existe um sentido forte de isenção, de respeito à autonomia, e mesmo do significado e representatividade dos conselheiros. A partir do momento em que estão inseridos naquele contexto, são e significam exatamente a mesma coisa. É evidente o respeito dos conselheiros de cidades mais bem preparadas e com maior representatividade política, com os conselheiros de municípios menores e menos organizados politicamente. É possível afirmar a partir desse entendimento, que a pactuação ou padrão de governança estabelecido propicia a territorialização do conselho da SDR de Blumenau. Mesmo que em vários sentidos o conselho expresse falhas estruturais que limitam sua atuação de forma mais ampliada, e que acabe deixando a desejar em algumas dimensões importantes, ainda assim faz com que se estabeleçam consistentemente as territorialidades anteriormente assinaladas.

Em qualquer ambiente em que se reúnem várias pessoas em torno de certo tema, com objetivos pré-definidos (como a proposta da própria SDR), evidentemente, estas relações são caracterizadas pela hipótese ou pelo entendimento particular de cada um dos participantes, mesmo que estes estejam submetidos a uma estrutura formal que determina os limites de atuação destes atores sociais. É possível perceber nas pautas de votação ou avaliação dos projetos que chegam ao conselho da SDR (cujo teor satisfaz evidentemente pré-requisitos básicos do ponto de vista documental, e que tratam de aspectos 
mais amplos, suprindo lacunas sociais em termos de atendimento, estrutura e infraestrutura), que estes são mais bem vistos. Claro que mesmo observadas todas as limitações da ação dos conselheiros, ainda assim, se reconhece o cuidado com a coisa pública. Não existe um pacto de mediocridade, ou seja, se há aprovação de uma proposta absurda de um determinado conselheiro, depois este se vê obrigado a votar em favor de outro na mesma proporção. Existe um avançado grau de compreensão e companheirismo entre os integrantes no que diz respeito ao entendimento das necessidades da região, do município inserido na região, fazendo parte de um grupo de municípios que devem funcionar harmonicamente, e isto sem dúvida qualifica o processo. Dessa forma podemos conceber que a SDR de Blumenau, em sua estrutura e tal como é conduzida, reforça a hipótese de isenção, parceria e companheirismo entre as cidades e seus respectivos representantes, fazendo com que os projetos sejam de interesse não só de cada município, mas, sobretudo da região, com forte apelo social, que atendam às necessidades dos territórios com significativa expressão e que representem o bem de uma porção significativa da população. Os temas que melhor transitam no conselho da SDR de Blumenau são os que versam sobre educação e saúde. Isto reflete o alto grau de preocupação com a satisfatória condição de vida das pessoas, o que estará refletido na região como um todo. Chama também a atenção o fato de que estas unidades de saúde ou educacionais devem representar investimentos estratégicos que venham a beneficiar a região. A exemplo disto podemos relembrar a importância do hospital universitário que tem tramitado naquela instância decisória e que servirá à região como um todo, absorvendo uma demanda por serviços de saúde que hoje acaba sendo distribuída nas unidades de saúde de Blumenau. 0 fato de que o hospital é vinculado à Universidade, que por sua vez tem importante função social, reitera sua própria razão de existir.

Da mesma forma que se enxerga os temas que transitam com maior facilidade pelo conselho, é possível também perceber o oposto, os projetos que não representam a vontade, o interesse e a melhoria para uma significativa parcela da sociedade integrada aos interesses regionais, encontram muita resistência entre os conselheiros. Isto não significa, entretanto, que em vários casos projetos sem argumento qualificador suficiente consigam aprovação no conselho da SDR, ainda que sob protestos de vários conselheiros; estes projetos podem acabar sendo aprovados por intervenção da esfera política.

Dentro do conselho da SDR de Blumenau, os conselheiros não percebem que a vinculação partidária de seus membros seja um aspecto determinante na condução das avaliações dos projetos bem como na definição da ordem de prioridades regionais. $\mathrm{Na}$ forma, no fluxo de funcionamento aparente ou visível da SDR, os conselheiros afirmam que o fato de haver um prefeito ou presidente da câmara de vereadores de determinada cidade que tem essa ou aquela vinculação política não representa em si argumento suficiente para definir os rumos das políticas de maneira diferente do que seria feito com os critérios definidos inicialmente, principalmente o do interesse social. Entretanto, em entrevista foi revelado que, sendo a SDR uma parte do poder e esta, caracterizada por ele, nos bastidores e de forma muito sutil, acaba ocorrendo este tipo de influência. O que ocorre é que os conselheiros, quando perguntados sobre esta questão, traduzem sua impressão com muita cautela e tentam desviar o olhar do real sentido da pergunta que implica em compreender se existe ou não fisiologismo nas relações dentro do conselho da SDR, propiciado por esfera política superior. Por outro lado, o que se vê no conselho da SDR é que existe uma participação muito maior de componentes políticas e governamentais do que na forma se expressa, na medida em que existem conselheiros sem poder de voto, mas vinculados ao governo, como por exemplo, comandantes de polícia militar, bombeiros. Ainda que representem instituições que devem em última instância defender, apoiar e proteger a população, estes conselheiros têm ligação íntima com o governo estadual; os comandantes já participam de esferas superiores e também tem seus interesses, que podem ser atendidos ou não em função de seu grau de alinhamento com quem detém o poder e controla os cargos, nas diversas instâncias e segmentos da sociedade.

Na percepção dos conselheiros, da mesma forma que a vinculação política ou o fato de um determinado conselheiro exercer determinado cargo político 
ou pertencer a algum partido não interfere no fluxo dos trabalhos, o fato de representar uma entidade de classe, também não significa que as políticas serão encaradas de outra forma ou que os projetos terão outro significado por representarem demandas de uma determinada categoria. Na realidade, como no caso da política, esta impressão fica na forma e não no conteúdo. Claro que o peso do voto de forma objetiva significa exatamente a mesma coisa. Mas é evidente também que, mesmo com o mesmo peso de voto, se respeita mais uma entidade do tipo Clube de Dirigentes Lojistas, ou a Associação Comercial e Industrial de um determinado município, basta analisar não só a quantidade de afiliados, mas a quantidade de recursos envolvida no movimento econômico destes representados e seu significado na atividade comercial e industrial da região. Será que este projeto, por não ter o mínimo apelo social e não representar em si uma prioridade regional indispensável, seria aprovado se não tivesse o respaldo dos componentes políticos e de entidade de classe? Então, a partir desta percepção, o fato da entidade de classe participar das pactuações, das negociações, fará diferença em maior ou em menor grau, dependendo da entidade e dependendo de como será a abordagem e defesa do projeto; no fim das contas, pode ser que pouco importe seu mérito ou a falta absoluta dele..

\section{Considerações Finais}

Embora os municípios da região do Vale, em sua maioria, estejam em situação relativamente boa no que se refere ao padrão de vida e desenvolvimento quando comparados com a média brasileira, seu desenvolvimento ocorreu e ocorre de forma desigual. Existem em nossa região territórios que por razões diversas conseguiram mais projeção política do que outros e por conseqüência, maior desenvolvimento em várias dimensões. Na lógica desenvolvimentista pregada ou proposta pela descentralização, se busca a equivalência dos municípios da região, de forma que as diferenças gradualmente sejam equacionadas. Ocorre que a proposta da criação das SDRs, embora inove com o desenho institucional, toma como ponto de partida as condições estruturais da dinâmica de poder que definiu o modelo que se hegemonizou historicamente. Ainda que potencialmente traga a proposta de superação por meio da horizontalização das representações e das interlocuções, com a contribuição das soluções proposta a partir da escala regional de proposição e gestão das agendas, podem-se fazer outras afirmações. Dentre elas que, pensando-se em uma perspectiva de avanços em relação a um modelo concentrador e autocrático, há um avanço. Se comparado a um modelo ideal de radicalização da democracia, há ainda muito por realizar. Do ponto de vista do modelo que o antecedeu, quando as demandas se apresentavam em nível de Fóruns de Desenvolvimento Regional, há quem afirme que houve um enrijecimento das agendas. Este estudo, entretanto, por sua proposição mais exploratória, consegue identificar no discurso dos atores atuais avanços importantes em relação à objetivação do senso de territorialidade, ao menos em uma dada perspectiva limitada do termo, uma vez que fica aberta a lacuna para maiores mergulhos acerca da correlação entre territorialidade e democracia, territorialidade e desenvolvimento, territorialidade e sustentabilidade. 0 que se tem assistido na história recente da região é uma polarização dos investimentos no município que concentra maior movimento econômico além de também ter o maior número de habitantes, que é o município de Blumenau. Isto sempre ocorreu assim com significativa intensidade, e mesmo os investimentos que eram feitos na região de Blumenau eram feitos em função das necessidades de Blumenau. Hoje, com a descentralização, ainda que se perceba este maior favorecimento, já é possível considerar, segundo a percepção dos entrevistados, maior atenção das esferas de poder com os municípios que integram a região e que tem menor peso político e econômico. Não só a relação de Blumenau com os outros municípios se alterou significativamente, como também as relações dos outros municípios entre si. Existe um declarado espírito de corpo que segue crescendo e que resulta numa relação muito mais próxima e próspera para todos. Este corpo regionalizado de atores, aprendendo a olhar seus temas ou agendas levando em consideração os demais, portanto numa acepção ampliada das políticas em curso, pode ser visto como a expressão de um senso de regionalidade que confere sustentação com progressividade do 
ponto de vista da legitimidade das agendas que de ali emergem. Hoje, o entendimento dos municípios que participam da SDR de Blumenau é de integração, de uma relação de compartilhamento de necessidades entendidas globalmente, de uma união de seus representantes na luta por causas comuns.

A governança em sua essência representa pactos decorrentes de relações em que não se faz juízo de valor. Ou seja, não se está tentando entender a validade ou virtuosidade das relações, o importante disso tudo é entender que, ocorrendo seja lá qual for o tipo de pacto, este, sem dúvida, produz resultados em termos de identidades e interesses dados ou emergentes. E, ao produto, aos resultados disso, denominamos territorialidades. As relações determinadas pelo aparato administrativo e político institucionalizado da SDR de Blumenau reúnem, num mesmo ambiente, pessoas que se submetem a discussões e que têm a intenção de alcançar seus objetivos (objetivos dos territórios que representam), que forçadamente devem entender e absorver como praxe o sentido de integração proposto pela política ou modelo das SDR. O resultado mais evidente, ou a territorialidade mais expressiva caracterizada no Conselho da SDR, é a política. A territorialidade política se caracteriza na medida em que os atores sociais daquele contexto discutem e negociam posições na tentativa de acomodar os interesses dos municípios que defendem ou representam, bem como, a contextualização das demandas dos municípios integrados ao princípio da regionalidade. Dessa forma, o resultado obtido pela depuração do aspecto político como fator integrador da regionalidade instituída pela SDR, caracteriza um formato também de coesão político-administrativa trazendo os municípios pertencentes à SDR de Blumenau a um patamar de maior representatividade e expressão em relação à realidade vivida por estes municípios antes de fazerem parte da secretaria. Apesar de o processo político estar em maturação, ele contribui para a integração, ou seja, o aprimoramento de práticas e relações entre os municípios membros e destes na sua relação com o poder central, caracterizado na figura do governo do estado e sua estrutura.

A proposta de descentralização do governo do estado promoveu uma grande modificação no modo como as agendas locais são consideradas pelo gover- no estadual. Neste sentido, tem produzido resultados perceptíveis quanto à contemplação das demandas regionalmente apresentadas, e um avanço quanto aos conteúdos considerados de interesse público. Se, em um primeiro momento, uma prática mais fisiológica de aprovações recíprocas amalgamou os primeiros passos de um senso de corpo, em fluxo, tanto as prioridades como as etapas pré-modernas de constituição do interesse público em termos processuais como determinante dos conteúdos passam também a ser problematizadas. Todas expressivas do mesmo senso de regionalidade da experiência em foco. Para além de uma análise localizada ou restritiva, procura-se aqui compreender o contexto por um viés mais sutilizado que nos oferece um extrato com maior subjetividade na percepção do conteúdo, do que nos ofereceria a simples análise da forma. O processo administrativo como um todo ocorre seguindo um fluxo pré-determinado que norteia (na forma) as ações dentro da estrutura e proposta do conselho da SDR de Blumenau; a essa altura importa menos, entretanto, o que ocorre nas entrelinhas do dia-a-dia da relação entre os conselheiros e o governo estadual. A referência feita ao processo administrativo, bem como ao seu fluxo pré-determinado não é gratuita, isto significa que os próprios limites de avaliação estão dados pela gênese do projeto em si. Dessa forma, o padrão de governança estabelecido e propiciado pela institucionalidade reflete o padrão de sustentação do processo de desenvolvimento, que poderia se traduzir, ainda que em caráter bastante provisório, em "sustentabilidade" dos processos, se os conteúdos em questão objetivamente se voltassem à premissa do desenvolvimento sustentável (Mantovaneli Jr e Sampaio, 2007). No caso estudado, da SDR de Blumenau, fica nítida a importância do padrão de governança como condicionante do desenvolvimento, que resulta da pactuação ocorrida naquela arena de discussões políticas. Na medida em que a SDR, enquanto arena instituída, como fórum oficial e legítimo das discussões e pactuações, alcança certo nível de sustentação política, propicia e tem a intenção de democratizar o processo decisório sobre as matérias avaliadas por ela, que em última instância representam a expressão de um conjunto social. Por outro lado, a sustentação administrativa (e não sustentabilidade, pelas mesmas razões acima 
apontadas) tem sua expressão maior caracterizada pela estrutura de gestão que permite a visibilidade do processo e, sobretudo, pela intencionalidade de redimensionar a si mesmo na medida em que a dinamicidade do contexto assim exigir. Mesmo que seja possível perceber que existam efetiva e significativamente fragilidades administrativas e políticas, o mérito da SDR é indiscutível e merece ser objeto de avaliações e sistematizações aprofundadas, que ensejem estudos propositivos, pois seu desenho institucional tem chamado a atenção dos atores ora considerados.

Estes apontaram, em função da existência da SDR de Blumenau, um avanço significativo do acesso das comunidades a serviços que, apesar de serem garantidos por lei aos cidadãos, apresentavam limitações operativas. Não queremos mostrar com este estudo que todos os problemas estejam sendo resolvidos pela intervenção do conselho da SDR, e sim que ela funciona como um canal de comunicação mais eficiente na proposição de suas demandas. Os impactos sociais decorrentes dos pactos estabelecidos no âmbito da SDR de Blumenau têm sido demonstrados em várias dimensões. Este estudo conseguiu evidenciar, por conseguinte, que o aprimoramento dos mecanismos de pactuação pode contribuir, por meio do fenômeno da governança pública, diretamente ou mediada pelos protagonistas diretamente envolvidos, com novas instâncias de territorialização, na medida em que são considerados em âmbito escalar ou multi escalar (local versus regional). As dinâmicas dos Conselhos de Desenvolvimento, ainda que possuam imensas lacunas estruturais e estruturantes, contribuem para um dado patamar e sedimentação e fluidez de interesses, ou sustentação política observáveis também enquanto, instâncias políticas de territorialização.

Retoma-se a noção de saúde, num sentido ampliado, entendo-a como fruto das relações sociais que estabelecem parâmetros de sustentabilidade do desenvolvimento, ou seja, o local, município, território e regional só podem ser considerados sadios, quando as pessoas que lá residem são também sadias.

\section{Referências}

ÁLVARES, E. et al. Governança corporativa: um modelo brasileiro. Rio de Janeiro: Elsevier, 2008.

BENTO, L. V. Governança e governabilidade na reforma do Estado: entre a eficiência e a democratização. Barueri, SP: Manole, 2003. COMISSÃO sobre Governança Global. Nossa comunidade global. Rio de Janeiro: Fundação Getúlio Vargas, 1996.

ETZIONI, A. Organizações modernas. São Paulo: Pioneira. 1980.

HAESBAERT, R. O mito da desterritorialização: o fim dos territórios a multiterritorialidade. 2. ed. Rio de Janeiro: Bertrand Brasil, 2006.

MANTOVANELI Jr., O.; SAMPAIO, C. A. C. Sustentabilidade política e administrativa: contribuições para a reformulação da agenda para o ecodesenvolvimento. Revista de Gestão Social e Ambiental, São Paulo, v. 1, n. 2, mai./ago., p. 3-21, 2007.

PHILIPPI Jr, A. Saúde, ambiente e sustentabilidade. In: QUARTAS SUSTENTÁVEIS, 27 maio 2009, Brasília. Palestra... Brasília: CDS/ PPG-CDS/UNB, 2009.

PROCOPIUCK, M.; FREY, K. Redes de políticas públicas e de governança e sua análise a partir da websphere analysis. Revista de Sociologia e Política, Curitiba, v. 17, n. 34, p. 63-83, 2009.

RAIDAN, A. La implementación de mecanismos de coordinación para la superar de los desafíosde la Gestión Pública. In: SEMINÁRIO DE RED MUNI: "NUEVO ROL DEL ESTADO, NUEVOROL DE LOS MUNICIPIOS”, 10., 2009, Ciudad de Buenos Aires. Annales... Buenos Aires: RED Muni, 2009. Disponível em: <http://biblioteca.municipios. unq.edu.ar/modules/mislibros/archivos/ RaidanRedMunizoog.pdf.>. Acesso em: 4 maio 2010. 
SACHS, I. Rumo à ecossocioeconomia: teoria e prática do desenvolvimento. Organização e tradução de P. H. F. VIEIRA. São Paulo: Cortez, 2007.

SAMPAIO, C. A. C. Pessoas sadias, municípios sadios: relatório. Blumenau, Brasília: Científico e Tecnológico (CNPq), 2001 (Projeto de Bolsa RecémDoutor).

SANTOS, M. Metamorfoses do espaço habitado: fundamentos teóricos e metodológicos da geografia (com a colaboração de ELIAS, D.). São Paulo: Hucitec, 1994.

SIEDENBERG, D. R. (Org.). Dicionário do desenvolvimento regional. Santa Cruz do Sul:

Edunisc, 2006.

WERTHEIN, J. A sociedade da informação e seus desafios. Ciência da Informação, Brasília, v. 29, n. 2, ago. 200o. Disponível em <http://www.scielo. br/scielo.php?script=sci_arttext\&pid=So1oo$19652000000200009 \& \operatorname{lng}=p t \& n r m=i s o>$. Acesso em: 4 maio 2010.

VIEIRA, P. F. Do ecodesenvolvimento ao desenvolvimento territorial sustentável. Política \& Sociedade, Florianópolis, n. 14, p. 27-55, abr. 2009. 